\title{
Studies on Ultimate Temperatures of Steel Columns Subjected to Thermal Elongations of Beams at a Fire
}

\author{
Fuminobu Ozaki ${ }^{1}$ and Takao Wakamatsu ${ }^{2}$ \\ ${ }^{1}$ Former Tokyo University Science \\ ${ }^{2}$ Tokyo University of Science
}

\begin{abstract}
Keywords : Fire Resistance performance, Ultimate temperature, Steel Column, Local buckling, Stub Column tests, FEM
\end{abstract}

\section{INTRODUCTION}

In this research, fire resistance performance of the steel columns that are influenced by the elongation of heated beams is discussed. Ultimate temperatures of columns are calculated by the analysis of a three-dimensional nonlinear FEM that uses 8 nodes rectanglar plate element.[1] The validity of equation which was proposed in order to estimate ultimate temperature of columns is examined.

\section{COMPARISON BETWEEN PAST RESULTS OF STEEL STUB COLUMN TEST AT HIGH TEMPERATURE AND NUMERICAL ANALYSIS RESULTS}

The validity of analysis in this research was examined by comparing results of analysis with the past results of steel stub column test at high temperature. In the experiment [2] that Hirasima and others carried out, box columns of SM490 are used as the specimens. The results showed the relation between the vertical displacement of the specimens and loads on the condition which load was increasing gradually at constant temperature(from room temperature to $600^{\circ} \mathrm{C}$ ). The number of the width thickness ratios of the specimens is two $(B / t=25,30)$.

In consideration of the symmetry of the specimens, the partial analysis model which consists of two steel plates of $1 / 4$ of sizes is used in the numerical analysis. The model is shown in Figure 3. The boundary condition of the top of the analytical model is assumed to be fixed end referring to the experimental conditions. In the experiment, $9 \mathrm{~mm}$ splice plates were welded to the edges of specimens in order to avoid the weld fracture in the edge part of specimens at high temperature. The analytical model which included the splice plates was used in this numerical analysis because the experiment results included the influence of this splice plates. Figure 1 shows the relations between stress and strain of steel at high temperatures. In the results of coupon tests (solid line), the values of stress increased rapidly especially at high temperature because strain rate was changed when strain was $0.5 \%$. The $\sigma-\varepsilon$ relations (broken lines) used in the numerical 
analysis neglected the rapid increase of the stress influenced by the change of strain rate. So, it was determined that the $\sigma^{-} \varepsilon$ relations will be in agreement with the value of stress which strain was $10 \%$.

Initial displacements of the lower end of the plate were set up in the analytical model shown in Figure 3. In the all analytical cases, it was determined that the displacements at the center part of plate were set to $1 / 1000 \times \mathrm{B}$.

Figure 2 shows the experiment results and the analysis results. The horizontal axis in the figure is the mean strain which the vertical displacement is divided by the total length of the specimen. The vertical axis the figure is the mean stress which loads is divided by the sectional area of the specimen. The analytical results are in good agreement with the experimental results at maximum stress and after buckling of column. Figure 3 shows the deformation drawing of the specimen after the specimen buckled locally. It shows that the deformation of local buckling is concentrated on the lower edge of the analytical model.
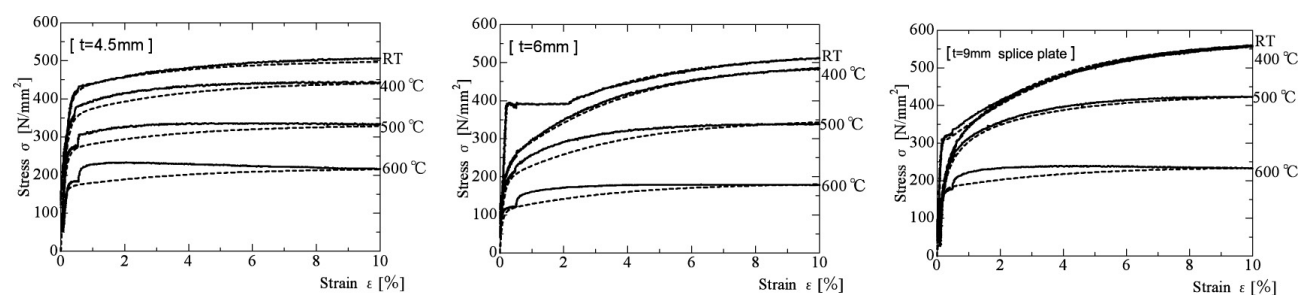

Figure 1 - $\sigma$ relation at high temperatures

(Solid line: Coupon Tests, Broken line: $\sigma-\varepsilon$ relation of FEM)
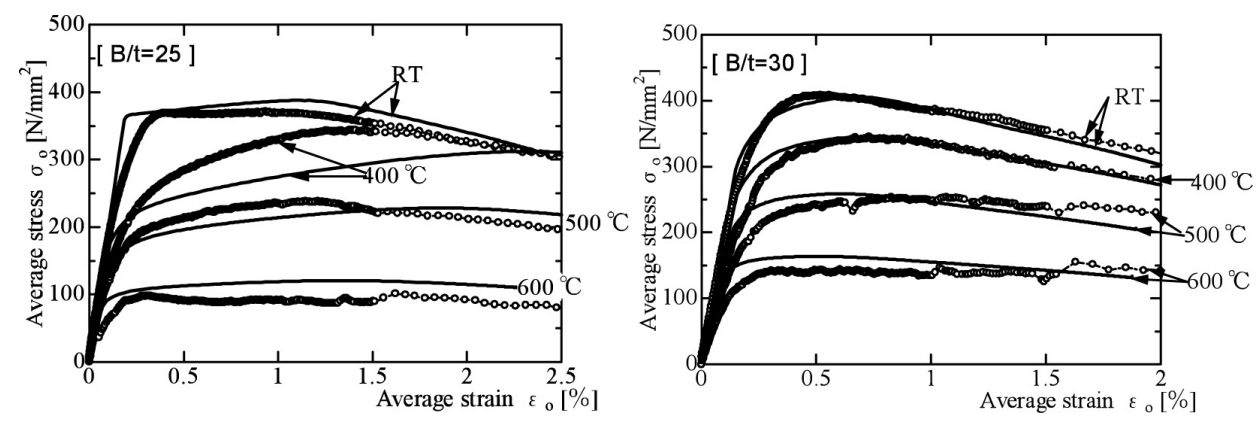

Figure 2 Comparison between the experiment results and the analysis results of Stub Columns ( $\mathrm{O}:$ the experiment result, Solid line: the analytical results.) 


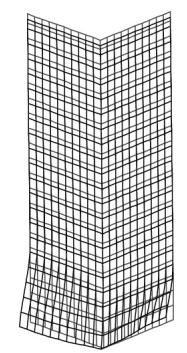

Figure 3 the deformation of the specimens after local buckling (Magnification of scale 1) $\left(B / t=30,600^{\circ} \mathrm{C}\right)$

\section{NUMERICAL ANALYSIS OF COLUMNTHAT IS INFLUENCE BYTHE EXPANSION OF HEATED BEAM}

The heated beam pushes the column connected with itself because of the thermal expansion of the beam during fire. The column receives the antisymmetric bending moment by the expansion, and local buckling may happen at the both of ends of column with increasing temperature of column. Local buckling of column easily occurs with the long span length of heated beam and the large width thickness ratio. When the evaluation of fire resistance performance of the columns is carried out, it is necessary to examine the influence by this deformation of the thermal expansion of beam.

Figure 4 shows the numerical analysis model that the column has the forced horizontal displacement at the top of itself.

Constant axial force $P$ act on the top of the column and the column is received the influence of the forced horizontal displacement $\delta_{H}$ that is assumed to be the expansion of heated beam. $\delta_{H}$ increases with the rise of the temperature of the member. The boundary conditions of both ends of column are assumed to be fixed end because the adjoining members that are kept room temperature strongly restrain the rotation of both ends of column. The width thickness ratio of the columns $B / T$ is 35 , and the height of the columns is $3,500 \mathrm{~mm}$ in this analysis. Steel grade is SM490, and the stress strain relations are obtained by equations that AIJ proposed [4]. Coefficient of thermal expansion of steel $\alpha$ is $12 \times 10^{-6}\left(1 /{ }^{\circ} \mathrm{C}\right)$. In this analysis, temperatures of column gradually increase uniformly. The temperature that the column collapses and is not able to bear the constant axial force $P$, is the analytical result of column (ultimate temperature). 


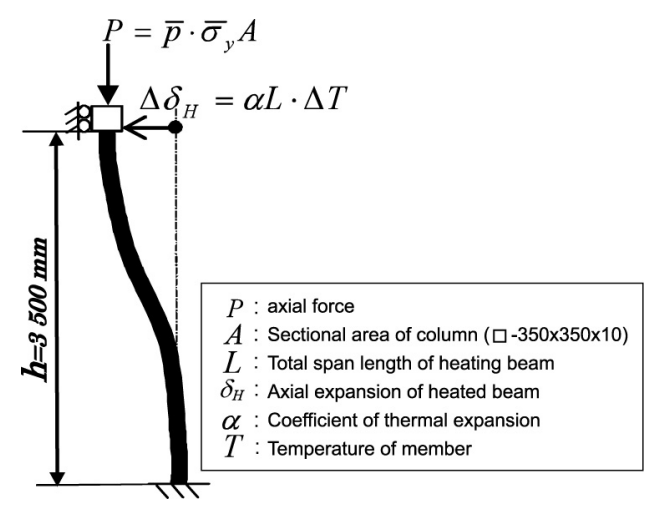

Figure 4 Numerical analysis models

\section{NUMERICAL ANALYSIS RESULTS}

Figure 5 shows the analysis results. A horizontal axis shows ratio of the length of the beam and the column $(\mathrm{L} / \mathrm{h})$. The vertical axis shows temperature $\left(T_{c r}\right)$ that the column collapsed. The analysis results are shown by the plots in this figure. The analysis results (o) that are obtained by using two dimensional beam elements are plotted in the figure for the reference. This two dimensional beam elements model doesn't include the influence of the stress reduction of the steel after local buckling. All collapse modes of these plots ( $\circ$ ) are total buckling of column.

It is thought that the gaps of temperature between (०) and (•) in Figure 5 almost correspond to the decrease of the ultimate temperature because of local buckling. The ultimate temperature that the column buckled locally $(\bullet)$ with large $\mathrm{L} / \mathrm{H}$ is lower one with small L/h. On the other hand, ultimate temperatures that the analysis (o) used the two dimensional beam element are not almost influence by the value of $\mathrm{L} / \mathrm{h}$. ultimate temperatures of the analysis that columns buckled locally $(\bullet)$ are lower than the total buckling temperatures of column based on tangent modulus theory (chain line)in the range of large $\mathrm{L} / \mathrm{h}$.

When $\mathrm{L} / \mathrm{h}$ is lower than 5 in the analysis, all ultimate temperatures of analysis are higher than temperatures(solid line and broken line) that include the influence of local buckling [3, 4]. Therefore, these equations evaluate ultimate temperature in safety side. 

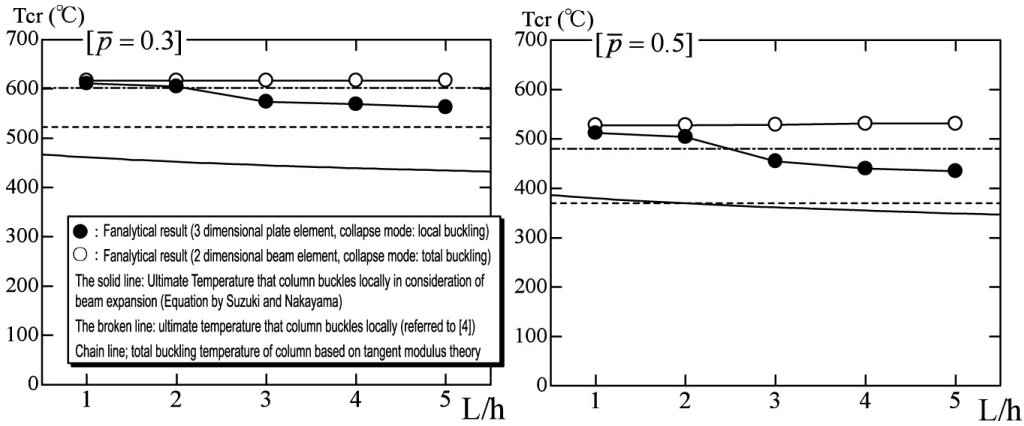

Figure 5 analysis results $(B / t=35)$

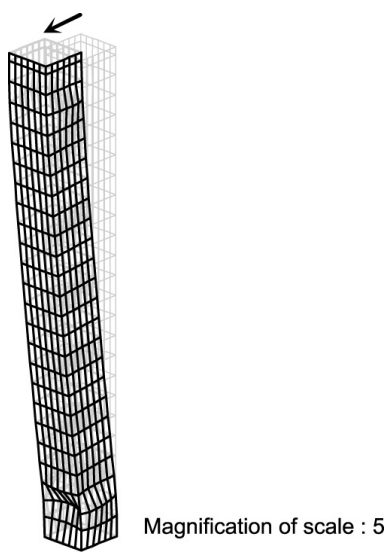

Figure 6 the deformation of the specimens

(Magnification of scale: 1) $(B / t=35, p=0.5, L / h=3)$

\section{ACKNOWLEDGEMENT}

In this research, precious results of stub column test at high temperature were provided by Professor Hirashima Takeo, Department of Engineering at The University of Chiba. We really appreciate what he provide the results.

\section{REFERENCES}

1. Ohsone Y., Suzuki H. Tanae J., Nakagawa H. and Nakayama H., "Ultimate Temperature of Steel Frames Subject to Fire: Part12 Development of Three Dimensional Elastic Plastic Stability of H Shaped Beams", Summaries of technical papers of Annual Meeting Architectural Institute of Japan. A-2, Fire safety, off-shore engineering and architecture, information systems technology, pp.57-58, 1995 (in Japanese) 
2. Hirashima T., Orimo T., KikutabS., Takahashi K., Hori A., Nakagome A., Matsudo M., Suzuki T., Yodhida M., Yamaouchi H. Nakamura K., Uesugi H. and Saito H., "A Study on Strength-Deformation Capacity of Steel Members at Elevated Temperature", Journal of Structural Engineering .B, Architectural Institute of Japan, Vol.46B, 2000 (in Japanese)

3. Nakayama H. and Suzuki H. Tanae J., Nakagawa H. and Ohsone Y., "Ultimate Temperature of Steel Frames Subject to Fire, Part11 Approximated Formulae for Strength Reduction due to Column Local Buckling", Summaries of technical papers of Annual Meeting Architectural Institute of Japan. A-2, Fire safety, off-shore engineering and architecture, information systems technology, pp.55-56, 1995 (in Japanese)

4. Architectural Institute of Japan, "Recommendation for Fire Resistant Design of Steel Structure", 1999 (in Japanese) 